\title{
Sepsis at ICU Admission Increases the ICU Mortality Rates Among Very Long ICU Stay Patients: A Secondary Analysis
}

\author{
Farshid Rahimibashar ${ }^{1}$, Mahmood Salesi², Amir Vahedian-Azimi ${ }^{3}$, Masoum Khosh Fetrat ${ }^{*}$ \\ ${ }^{1}$ Department of Anesthesiology and Critical Care, School of Medicine, Hamadan University of Medical Sciences, \\ Hamadan, Iran \\ ${ }^{2}$ Chemical Injuries Research Center, Life Style Institute, Baqiyatallah University of Medical Sciences, Tehran, Iran \\ ${ }^{3}$ Trauma Research Center, Nursing Faculty, Baqiyatallah University of Medical Sciences, Tehran, Iran \\ ${ }^{4}$ Department of Anesthesiology and Critical Care, Khatamolanbia Hospital, Zahedan University of Medical Sciences, \\ Zahedan, Iran
}

*Corresponding Author: Masoum Khosh Fetrat, M.D., Associate Professor, Department of Anesthesiology and Critical Care, Khatamolanbia Hospital, Zahedan University of Medical Sciences, Zahedan, Iran. Tel: +98-9196017138, Email: drkhoshfetrat@yahoo.com

Received October 13, 2020; Accepted December 13, 2020; Online Published December 21, 2020

\begin{abstract}
Background: Sepsis is a very common serious medical condition among patients admitted to the intensive care units (ICUs) that increases with age and ICU length of stay (LOS).

Objectives: The primary goal of this study was to estimate the mortality rate due to sepsis among adult patients admitted to the mixed medical-surgical ICUs for a long time. The secondary goal was to identify factors associated with predicting ICU mortality in individuals with long-term ICU LOS.

Methods: Adult patients admitted to the medical ICU for a long time ( $\geq 75$ days) were included in this retrospective secondary analysis study. Baseline demographic, clinical, and laboratory data were recorded upon inclusion in the study.

Results: ICU mortality occurred in 78 (43.1\%) patients, out of 188 participants. A greater portion of patients with sepsis at admission $(62.7 \%)$ were observed in the death group $(59.2 \%$ vs. $30.8 \%, P<0.001)$, than the survivor group. Additionally, survived patients differed significantly in terms of age, family engagement, baseline cognitive impairment, activity, nurse anticipated turnover scale (ATS), duration of a mechanical ventilator (MV), and ICU LOS. The results of multivariate binary logistic regression showed that the older age and low family intervention can increase the risk of mortality in patients with sepsis at the time of admission, with a long ICU LOS.

Conclusion: Our findings are crucially important to increase the awareness of the impact of sepsis, highlight the need for continued research into potential preventive and therapeutic interventions, and help guide resource allocation.

Keywords: Sepsis, Intensive Care Unit, Severity of Illness, Outcome, Mortality
\end{abstract}

\section{Background}

The mortality rate of patients admitted to the intensive care units (ICUs) varies and depends on several variables, including the severity of the disease, the number, and severity of organ failure, age, the health status of patients, and the nature and source of infection. ${ }^{1}$ Sepsis is one of the major causes of morbidity and mortality in ICUs., ${ }^{2,3}$ Sepsis develops when the host's response to infection becomes deregulated and leads to life-threatening organ dysfunction. ${ }^{4}$ Early recognition and management of sepsis have challenged emergency care and critical care physicians and nurses. ${ }^{5,6}$ According to previous studies, ICU mortality rates in patients with sepsis were approximately $26 \%$ to $55 \%$ and were twice as high as those in non-septic patients. ${ }^{7-9}$ A study by Brun-Buisson et $\mathrm{al}^{10}{ }^{10}$ showed that the ICU mortality rate in 30 days was 35\%, while for two months of hospitalization it increased up to $41.9 \%$. Therefore, sepsis is a very common medical condition among critically ill patients in the ICU, and the mortality rate due to sepsis increases with the prolonged length of stay (LOS) in the ICU.

Although sepsis is the leading cause of mortality in ICUs, information regarding the effect of sepsis at the ICU admission on mortality is limited. Recently a multicenter, prospective, observational, post hoc analysis study was conducted on very old intensive care patients ( $\geq 80$ years) with short ICU LOS ( $\leq 4$ days), in which the authors reported unadjusted 30-day survival that was not significantly different between patients with and without sepsis at the admission. ${ }^{11}$ Additionally, after adjustment

Copyright (C 2020 The Author(s). This is an open-access article distributed under the terms of the Creative Commons Attribution License (http:// creativecommons.org/licenses/by/4.0), which permits unrestricted use, distribution, and reproduction in any medium, provided the original work is properly cited. 
for age, gender, frailty, and the Sequential Organ Failure Assessment (SOFA) score, sepsis had no impact on 30-day survival; moreover, a cox proportional hazard regression model stratified on the matched pairs showed that 30-day survival was similar in both groups. However, based on evidence, sepsis survivors are more frequently discharged from hospital and often experience long-term outcomes such as late mortality, immune dysfunction, secondary infections, impaired quality of life, and unplanned readmissions. ${ }^{12}$ Although hospital readmissions after sepsis are common, associated risk factors and how to manage patients who survive an episode of sepsis still need clarification. ${ }^{13,14}$ Therefore, sepsis-associated longterm outcomes, including late mortality have attracted increasing attention.

\section{Objectives}

To investigate the effect of sepsis at the admission on mortality of ICU patients with long-term ICU LOS, we conducted this retrospective secondary analysis study. In addition, we identified the factors associated with predicting ICU mortality in these patients.

\section{Methods}

\subsection{Study Design and Participants}

This study was a retrospective secondary analysis of the part of a much bigger project that was a prospective longitudinal cohort study. ${ }^{15}$ In brief, the original study was a prospective longitudinal cohort study which was conducted over 4200 mixed medical-surgical ICUs patients on MV from two academic teaching hospitals in Tehran, Iran between June 1, 2007 and October 31, 2015. ${ }^{15}$ Herein is reported a retrospective secondary analysis of 181 patients from the mixed medical-surgical ICUs of two academic medical centers to assess the impact of sepsis at ICU admission and to identify predictive factors for ICU mortality in very long ICU stay patients. The inclusion criteria were $(a)$ age $\geq 18$ years, (b) ICU LOS $\geq 75$ days, and $(c)$ full-code status patients. The original study was approved by the Investigative Review Board at Baqiyatallah University of Medical Sciences, Tehran, Iran (IR.BMSU. REC.1394.451), and Shariati Hospital of Tehran University of Medical Sciences, Tehran, Iran. The patients, or their relatives were informed about participation in the study by the physician at the time of admission with consent in all cases. All study parts were reviewed according to the "strengthening the reporting of observational studies in epidemiology for respondent-driven sampling studies" (STROBE-RDS) statement. ${ }^{16}$

\subsection{Definition}

Patients were included in the sepsis category according to clinical criteria. Clinical criteria adopted since 2015 are "suspected or documented infection and an acute increase of $\geq 2$ Sequential (Sepsis-related) Organ Failure Assessment (SOFA) points (a proxy for organ dysfunction)". It was updated in 2016 in sepsis-3 criteria (4): "Sepsis is a life- threatening organ dysfunction caused by a dysregulated host response to infection. For clinical operationalization, organ dysfunction can be represented by an increase in the SOFA score of two points or more, which is associated with an in-hospital mortality greater than $10 \%$ ”.

The cut-off to find the patients with long term ICU LOS was estimated using receiver operating characteristic (ROC) Analysis. Consensus threshold values for what constitutes very-long ICU LOS has not been described to date. In this study, optimal thresholds were selected by ROC analysis of a database of 4200 ICU patients. To achieve a sensitivity of $95 \%$ and a specificity of $90 \%$, a threshold of $\geq 75$ ICU days was observed to have the best ROC characteristics. Threshold selection was discussed in a qualitative panel of 12 members, including one psychiatrist, one psychologist, three intensivists, one neurologist, two internists, two anesthesiologists, and two ICU nurses. It was consensually agreed that based on the available data, an ICU stay $\geq 75$ days constitutes a very-long ICU stay in this region of Iran. Finally, based on inclusion criteria, we recognized 181 patients with long ICU LOS over 75 days from 4200 participants.

\subsection{Data Collection and Outcome}

Demographic and clinical characteristics were recorded for these 118 patients, including age, gender, sepsis based on sepsis-3 criteria (4), baseline cognitive impairment (CI) determined by the six-item cognitive impairment test (6CIT), ${ }^{17}$ comorbidities based on Charlson Comorbidity Index, ${ }^{18}$ activity and mobility measured with the Perme ICU mobility score (IMS) ${ }^{19}$ family engagement determined according to family bedside presence $\geq 2$ hours daily, ${ }^{20}$ staff burnout and anticipated turnover measured with the anticipated turnover scale (ATS) questionnaire, ${ }^{21}$ acute nursing care determined by requiring $>8$ hours nursing care in an 8 hour shift, ICU LOS, sedative dose which was determined in accordance with published recommendations, ${ }^{22}$ physical restraint application, baseline sleep disturbance assessed with the Pittsburgh Sleep Quality Index (PSQI), ${ }^{23}$ ambient noise level and use of an alarm silence strategy were assessed using the TES 1352A sound level meter (SLM) device (TES Electrical Electronic Corp., Taiwan) with a range of 30-130 decibel (dB). ${ }^{24}$ Additionally, illness severity was measured by the Acute Physiology and Chronic Health Evaluation (APACHE) IV, SOFA, and Simplified Acute Physiology Score (SAPS) at the day of admission, at 14th and 28th days. ${ }^{25,26}$ The main outcome variable was ICU mortality, following ICU admission.

\subsection{Statistical Analysis}

All analyses were performed using IBM $^{\circledR}$ SPSS $^{\circledR} 23.0$ (IBM Corp., Armonk, NY) and GraphPad Prism $5^{\circledR}$ (GraphPad Software Inc., La Jolla, CA). ${ }^{27}$ Descriptive statistics were calculated for all variables. Categorical variables were expressed as counts (percentage) and continuous variables as mean \pm standard deviation (SD). Patients were stratified 
one time as septic and non-septic groups and the second time by the occurrence of mortality as survivor or nonsurvivor during the ICU LOS, and demographic and clinical characteristics were assessed using $t$ test with continuous variable and chi-square, or Fisher exact test (as appropriate) with categorical variables. Furthermore, univariate and multivariate binary logistic regression models were used to assess the prediction of ICU mortality in individuals with long term ICU LOS. All tests were twotailed, with a significance level of $P<0.05$.

\section{Results}

A total of 181 critically ill patients with a very long ICU LOS ( $\geq 75$ days) were included in the analysis. Of these, 61 were male (33.7\%) and $120(66.3 \%)$ were female. The mean \pm SD age of total participants was $64.92 \pm 5.18$ years and more than half of the patients were over 65 years (51.2\%).
Of a total of one hundred and eighty patients, 85 (47\%) and 96 (53\%) patients were recognized as septic and nonseptic groups, respectively. Demographic and clinical characteristics of participants according to septic and nonseptic groups are presented in Table 1. The results showed that there was no significant difference between the septic and non-septic groups in terms of demographic and clinical characteristics. However, in terms of outcome, the results revealed that the mortality rate was significantly higher in the septic patients compared to non-septic patients groups (71.8\% vs. $25.5 \%, P<0.001)$.

Demographic and clinical characteristics of participants according to the outcome are presented in Table 2. ICU mortality has occurred in 78 (43.1\%) participants. Survived patients differed significantly in terms of age, family engagement, baseline cognitive impairment, activity, nurse ATS, duration of a mechanical ventilator (MV), and ICU

Table 1. Demographic and Clinical Characteristics According to Septic and Non-septic Participants

\begin{tabular}{|c|c|c|c|c|}
\hline \multirow{2}{*}{ Variables } & \multicolumn{2}{|c|}{ Patients } & \multirow{2}{*}{ Total patients $(\mathrm{n}=181)$} & \multirow{2}{*}{$P$ Value } \\
\hline & Septic $(n=85)$ & Non-septic $(n=96)$ & & \\
\hline Age, mean $\pm \mathrm{SD}(\mathrm{y})$ & $65.07 \pm 5.04$ & $64.79 \pm 4.32$ & $64.92 \pm 5.18$ & 0.719 \\
\hline Gender, female, n (\%) & $57(67.1)$ & $63(65.6)$ & $120(66.3)$ & 0.839 \\
\hline Family engagement, high, $\mathrm{n}(\%)^{\mathrm{a}}$ & $27(31.8)$ & $20(20.8)$ & $47(26)$ & 0.094 \\
\hline Baseline cognitive impairment, yes, $\mathrm{n}(\%)^{\mathrm{b}}$ & $15(17.6)$ & $12(12.5)$ & $27(14.9)$ & 0.332 \\
\hline Baseline sleep disturbance, yes, $\mathrm{n}(\%)^{\mathrm{c}}$ & $55(64.7)$ & $67(69.8)$ & $122(67.4)$ & 0.466 \\
\hline Comorbidities, yes, $\mathrm{n}(\%)^{\mathrm{d}}$ & $16(18.8)$ & $16(16.7)$ & $32(17.7)$ & 0.704 \\
\hline Activity, high, n (\%) ${ }^{\mathrm{e}}$ & $38(44.7)$ & $34(35.4)$ & $72(39.8)$ & 0.203 \\
\hline Physician ATS, $\leq 35(\%)^{f}$ & $55(64.7)$ & 59 (61.5) & $114(63.0)$ & 0.652 \\
\hline Nurse ATS, $\leq 35(\%)^{f}$ & $27(31.8)$ & $20(20.8)$ & $47(26.0)$ & 0.094 \\
\hline Noise of invasive procedures, $>40 \mathrm{~dB}, \mathrm{n}(\%)$ & $13(15.3)$ & $8(8.3)$ & $21(11.6)$ & 0.114 \\
\hline Noise related to others ${ }^{*},>40 \mathrm{~dB}, \mathrm{n}(\%)^{\mathrm{g}}$ & $29(34.1)$ & $40(41.7)$ & $69(38.1)$ & 0.297 \\
\hline Alarm silence strategy, $<40 \mathrm{~dB}, \mathrm{n}(\%)$ & $11(12.9)$ & $6(6.3)$ & $17(9.4)$ & 0.124 \\
\hline Sedation, high dose, $\mathrm{n}(\%)$ & $19(22.4)$ & $20(20.8)$ & $39(21.5)$ & 0.804 \\
\hline Level of nursing care, high, $\mathrm{n}(\%)^{\mathrm{h}}$ & $23(27.1)$ & $26(27.1)$ & $49(27.1)$ & 0.997 \\
\hline Application of physical restraint, yes, n (\%) & $40(47.1)$ & $49(51)$ & $89(49.2)$ & 0.593 \\
\hline APACHE IV score, mean \pm SD (first day) & $24.9 \pm 2.38$ & $24.5 \pm 2.00$ & $24.66 \pm 2.19$ & 0.232 \\
\hline APACHE IV score, mean \pm SD $\left(14^{\text {th }}\right.$ day $)$ & $35.3 \pm 4.67$ & $35.2 \pm 4.13$ & $35.25 \pm 4.38$ & 0.962 \\
\hline APACHE IV score, mean \pm SD $\left(28^{\text {th }}\right.$ day $)$ & $25.47 \pm 4.56$ & $24.71 \pm 4.59$ & $25.07 \pm 4.62$ & 0.276 \\
\hline SOFA score, mean $\pm \mathrm{SD}$ (first day) & $15.03 \pm 3.44$ & $15.19 \pm 3.15$ & $15.12 \pm 3.28$ & 0.741 \\
\hline SOFA score, mean $\pm S D\left(14^{\text {th }}\right.$ day $)$ & $14.06 \pm 3.46$ & $14.78 \pm 3.07$ & $14.69 \pm 3.25$ & 0.710 \\
\hline SOFA score, mean $\pm \mathrm{SD}\left(28^{\text {th }}\right.$ day $)$ & $14.85 \pm 3.53$ & $15.01 \pm 3.36$ & $14.93 \pm 3.43$ & 0.768 \\
\hline SAPS score, mean \pm SD (first day) & $33.25 \pm 7.56$ & $32.14 \pm 6.66$ & $32.66 \pm 7.10$ & 0.294 \\
\hline SAPS score, mean \pm SD ( $14^{\text {th }}$ day $)$ & $43.83 \pm 7.71$ & $44.02 \pm 8.83$ & $43.93 \pm 8.30$ & 0.881 \\
\hline SAPS score, mean \pm SD (28 $8^{\text {th }}$ day $)$ & $38.69 \pm 8.06$ & $39.05 \pm 6.68$ & $38.35 \pm 7.35$ & 0.559 \\
\hline Duration of $\mathrm{MV}$, mean $\pm \mathrm{SD}$ (hours) & $857.48 \pm 153.7$ & $846.20 \pm 99.24$ & $851.5 \pm 127.52$ & 0.554 \\
\hline ICU LOS, mean \pm SD (day) & $77.95 \pm 13.97$ & $76.93 \pm 9.02$ & $77.41 \pm 11.59$ & 0.554 \\
\hline Mortality rate, n (\%) & $61(71.8)$ & $24(25.5)$ & $78(43.1)$ & $<0.001^{*}$ \\
\hline
\end{tabular}

Abbreviations: APACHE IV means Acute Physiology and Chronic Health Evaluation IV; SOFA means Sequential Organ Failure Assessment; MV means mechanical ventilator; LOS means length of stay; ${ }^{*}$ noise related to the nursing stations, staff conversation in patients' bedside and medical devices; ${ }^{*}$ statistically significant. ${ }^{a}$ As determined by having family at bedside for $\geq 2$ hours daily; ${ }^{b}$ As determined by the six-item cognitive impairment test (6-CIT) and $>8$ score significant as cognitive impairment; ${ }^{\mathrm{c}}$ As determined by the Pittsburgh Sleep Quality Index (PSQI) and PSQI score $>5$ indicate worse sleep quality ; ${ }^{\mathrm{d}}$ As determined by the Charlson Comorbidity Index based on the International Classification of Diseases (ICD) that a score of zero indicates that no comorbidities were found and the higher the score shows comorbidity; ${ }^{\mathrm{e}}$ As determined by the ICU mobility score (IMS) is scored from 0 to 10 , with a score of 0 to 4 meaning low mobility, 4 to 8 moderate mobility and a score between 8 and 10 meaning high mobility; ${ }^{f}$ As determined by the anticipated turnover scale (ATS); ${ }^{g}$ Noise related to the nursing stations, staff conversation in patients' bedside and medical devices, ${ }^{\mathrm{h}}$ As determined by requiring $>8$ hours nursing care in an 8 hour shift. 
Table 2. Demographic and Clinical Characteristics of the Participants According to Outcomes

\begin{tabular}{|c|c|c|c|c|}
\hline \multirow{2}{*}{ Variables } & \multicolumn{2}{|c|}{ Outcome } & \multirow{2}{*}{$\begin{array}{c}\text { Total patients } \\
\quad(n=181)\end{array}$} & \multirow{2}{*}{$P$ value } \\
\hline & Death $(n=78)$ & Alive $(n=103)$ & & \\
\hline Age, mean \pm SD $(y)$ & $65.91 \pm 5.42$ & $63.61 \pm 4.56$ & $64.92 \pm 5.18$ & $0.003^{*}$ \\
\hline Gender, female, n (\%) & $49(62.8)$ & $71(68.9)$ & $120(66.3)$ & 0.398 \\
\hline Family engagement, high, $\mathrm{n}(\%)^{\mathrm{a}}$ & $11(14.1)$ & $36(35.0)$ & $47(26)$ & $0.002 *$ \\
\hline Baseline cognitive impairment, yes, $\mathrm{n}(\%)^{\mathrm{b}}$ & $21(20.4)$ & $6(7.7)$ & $27(14.9)$ & $0.018^{*}$ \\
\hline Baseline sleep disturbance, yes, $n(\%)^{c}$ & $51(65.4)$ & $71(68.9)$ & $122(67.4)$ & 0.614 \\
\hline Comorbidities, yes, n (\%) ${ }^{d}$ & $22(21.4)$ & $10(12.8)$ & $32(17.7)$ & 0.136 \\
\hline Activity, high, $\mathrm{n}(\%)^{\mathrm{e}}$ & $24(30.8)$ & $48(46.6)$ & $72(39.8)$ & $0.031^{*}$ \\
\hline Sepsis at ICU admission, yes, $\mathrm{n}(\%)$ & $61(59.2)$ & $24(30.8)$ & $85(47.0)$ & $<0.001^{*}$ \\
\hline Physician ATS, $\leq 35(\%)^{f}$ & $49(62.8)$ & $65(63.1)$ & $114(63.0)$ & 0.968 \\
\hline Nurse ATS, $\leq 35(\%)^{f}$ & $36(35.0)$ & $11(14.1)$ & $47(26.0)$ & $0.002 *$ \\
\hline Noise of invasive procedures, $>40 \mathrm{~dB}, \mathrm{n}(\%)$ & $5(6.4)$ & $16(15.5)$ & $21(11.6)$ & 0.058 \\
\hline Noise related to others $\mathrm{s}^{*}>40 \mathrm{~dB}, \mathrm{n}(\%)^{\mathrm{g}}$ & $26(33.3)$ & $43(41.7)$ & $69(38.1)$ & 0.248 \\
\hline Alarm silence strategy, $<40 \mathrm{~dB}, \mathrm{n}(\%)$ & $7(9.0)$ & $10(9.7)$ & $17(9.4)$ & 0.867 \\
\hline Sedation, high dose, $\mathrm{n}(\%)$ & $19(24.4)$ & $20(19.4)$ & $39(21.5)$ & 0.423 \\
\hline Level of nursing care, high, $\mathrm{n}(\%)^{\mathrm{h}}$ & $21(26.9)$ & $28(27.2)$ & $49(27.1)$ & 0.969 \\
\hline Application of physical restraint, yes, n (\%) & $55(53.4)$ & $34(43.6)$ & $89(49.2)$ & 0.191 \\
\hline $\mathrm{APACHE} I V$ score, mean $\pm \mathrm{SD}$ (first day) & $24.64 \pm 2.19$ & $24.68 \pm 2.20$ & $24.66 \pm 2.19$ & 0.907 \\
\hline APACHE IV score, mean \pm SD $\left(14^{\text {th }}\right.$ day $)$ & $34.83 \pm 4.5$ & $35.57 \pm 4.28$ & $35.25 \pm 4.38$ & 0.262 \\
\hline $\mathrm{APACHE}$ IV score, mean $\pm \mathrm{SD}\left(28^{\text {th }}\right.$ day $)$ & $25.44 \pm 4.7$ & $24.78 \pm 4.51$ & $25.07 \pm 4.62$ & 0.341 \\
\hline SOFA score, mean \pm SD (first day) & $14.78 \pm 3.39$ & $15.37 \pm 3.19$ & $15.12 \pm 3.28$ & 0.228 \\
\hline SOFA score, mean $\pm \mathrm{SD}\left(14^{\text {th }}\right.$ day $)$ & $14.35 \pm 3.34$ & $14.95 \pm 3.17$ & $14.69 \pm 3.25$ & 0.226 \\
\hline SOFA score, mean $\pm \mathrm{SD}\left(28^{\text {th }}\right.$ day $)$ & $14.53 \pm 3.56$ & $15.24 \pm 3.32$ & $14.93 \pm 3.43$ & 0.173 \\
\hline SAPS score, mean \pm SD (first day) & $33.08 \pm 7.83$ & $32.34 \pm 6.51$ & $32.66 \pm 7.10$ & 0.489 \\
\hline SAPS score, mean \pm SD ( $14^{\text {th }}$ day $)$ & $43.44 \pm 9.09$ & $44.30 \pm 7.68$ & $43.93 \pm 8.30$ & 0.496 \\
\hline SAPS score, mean \pm SD (28 $8^{\text {th }}$ day $)$ & $38.88 \pm 7.75$ & $37.95 \pm 7.03$ & $38.35 \pm 7.35$ & 0.399 \\
\hline Duration of $\mathrm{MV}$, mean $\pm \mathrm{SD}$ (hours) & $868.36 \pm 157.87$ & $829.23 \pm 64.17$ & $851.5 \pm 127.52$ & $0.041^{*}$ \\
\hline ICU LOS, mean \pm SD (day) & $75.38 \pm 5.83$ & $78.94 \pm 14.35$ & $77.41 \pm 11.59$ & $0.041^{*}$ \\
\hline
\end{tabular}

Abbreviations: APACHE IV means Acute Physiology and Chronic Health Evaluation IV; SOFA means Sequential Organ Failure Assessment; MV means mechanical ventilator; LOS means length of stay; ${ }^{*}$ noise related to the nursing stations, staff conversation in patients' bedside and medical devices; ${ }^{*}$ statistically significant. As determined by having family at bedside for $\geq 2$ hours daily; ${ }^{\mathrm{b}}$ As determined by the six-item cognitive impairment test (6-CIT) and $>8$ score significant as cognitive impairment; ' As determined by the Pittsburgh Sleep Quality Index (PSQI) and PSQI score $>5$ indicate worse sleep quality ; ${ }^{\mathrm{d}}$ As determined by the Charlson Comorbidity Index based on the International Classification of Diseases (ICD) that a score of zero indicates that no comorbidities were found and the higher the

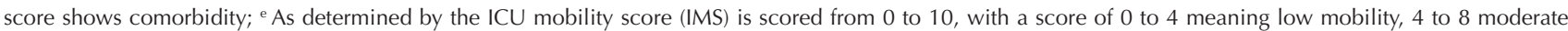
mobility and a score between 8 and 10 meaning high mobility; ${ }^{f}$ As determined by the anticipated turnover scale (ATS); ${ }^{g}$ Noise related to the nursing stations, staff conversation in patients' bedside and medical devices, ${ }^{\text {h }}$ As determined by requiring $>8$ hours nursing care in an 8 hour shift.

LOS. Additionally, a greater portion of patients with sepsis at admission $(62.7 \%)$ were observed in the death group (59.2\% vs. $30.8 \%, P<0.001)$. Other characteristics did not differ significantly between groups $(P>0.05)$. The results of the univariate and multivariate binary logistic regression analyses to predict the risk factors for in-hospital mortality are presented in Figure 1. On multivariate analysis, patients were at increased risk of ICU mortality as follows: (1) had sepsis at ICU admission (odds ratio [OR] 3.305, 95\% CI: 1.694-6.448, $P<0.001$ ), (2) older age (OR 1.084, 95\% CI: $1.010-1.163, P=0.025$ ), and (3) lower family engagement (OR 2.781, 95\% CI: 1.234-6.266, $P=0.014$ ).

\section{Discussion}

This study was aimed at estimating the mortality rate among adult patients admitted in the mixed medicalsurgical ICUs with or without sepsis at admission and also identifying risk factors which are predictors of mortality in patients with long term ICU LOS ( $\geq 75$ days). The mortality rate was found to be $43.1 \%$ in this study. The results revealed that the mortality rate was significantly higher in the septic patients compared to non-septic patients groups. Furthermore, there was a significant difference in mean age, family engagement, baseline cognitive impairment, activity score, sepsis at ICU admission, nurse ATS, and duration of MV among survivors and non-survivors. On multivariate binary logistic regression analysis, older age, having sepsis at ICU admission, baseline cognitive impairment, and low family engagement were identified to be independent predictor factors of ICU mortality. The mortality rate was significantly higher in the age group over 65 years, approximately $60 \%$. A total of 85 (47\%) patients had sepsis at ICU admission and a significantly higher rate of mortality occurred in patients with sepsis. The 

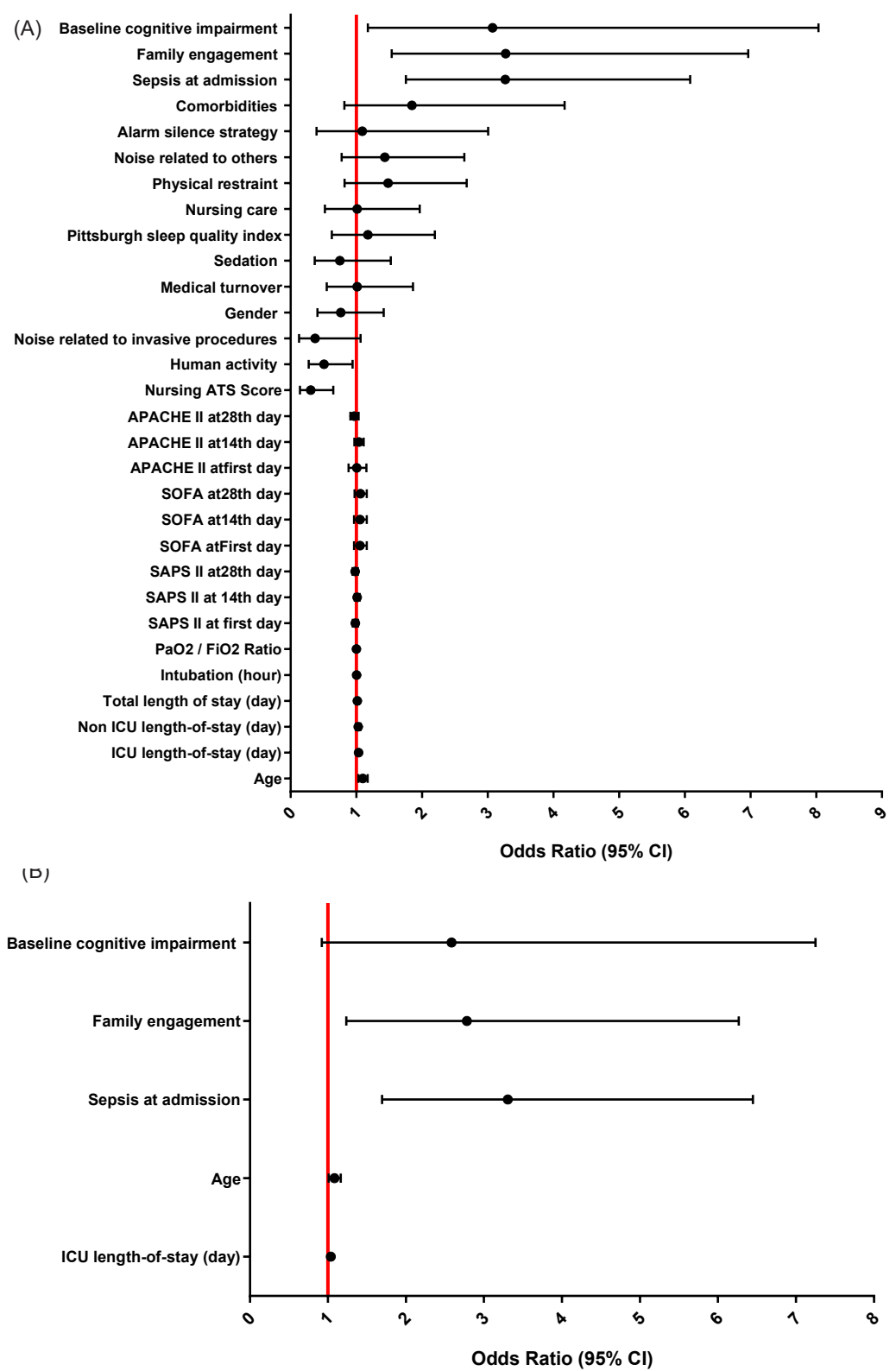

Figure 1. Univariate (A) and Multivariate (B) Binary Logistic Regression Analyses to Identify Predictive Factors for ICU Mortality.

death occurred in $21(87.5 \%)$ of 24 patients with baseline cognitive impairment. Moreover, patients with low family engagement $\geq 2$ hours daily had a higher risk of mortality.

Similar to our findings, a study by Colpan et $\mathrm{al}^{28}$ reported the most important risk factors of ICU mortality as older age, mechanical ventilation, enteral nutrition, tracheostomy, and sepsis. In a 6-month prospective observational study by Chen et al, ${ }^{29}$ in the medical and surgical ICUs of a 1800-bed university hospital, multivariate logistic regression analysis demonstrated that the presence of systemic inflammatory response syndrome at the time of ICU entry, APACHE II score on ICU Day 4, parenteral nutrition and sepsis were independently associated with ICU mortality. In addition, our findings were consistent with previous studies that showed worsening outcome of critically ill patients with sepsis. ${ }^{3}$
To our knowledge, this is the first study reporting the mortality rates in critically ill patients with or without sepsis at the ICU admission who have been hospitalized in the ICU for a long time. Additionally, the other strengths of our study included its multi-center design as well as having a non-septic patients group. However, our study has several limitations. Firstly, data were collected prospectively in the main study, ${ }^{15}$ but data analysis on septic and non-septic patients was performed retrospectively. Secondly, the focus of infection was not registered and the occurrence of sepsis after ICU admission was neither reported. Nevertheless, our results provide insight into the outcome and factors associated with ICU mortality in very long ICU stay patients with sepsis at admission compared to patients without sepsis at ICU admission. 


\section{Research Highlights}

\section{What Is Already Known?}

Sepsis is a very common serious medical condition among patients admitted to the ICUs, and its mortality rate increases with the prolonged LOS in the ICU. It develops when the host's response to infection becomes deregulated and leads to life-threatening organ dysfunction.

\section{What This Study Adds?}

The older age and low family intervention can increase the risk of mortality in patients with sepsis at the time of admission, with a long ICU LOS. It was found that there was no significant difference between the septic and non-septic groups in terms of demographic and clinical characteristics.

\section{Conclusion}

This multi-center retrospective observational second analysis study revealed that the sepsis, age, and low family engagement were the independent factors associated with ICU mortality in very long ICU LOS patients. Our findings are crucially important to increase awareness of the impact of sepsis, highlight the need for continued research into potential preventive and therapeutic interventions, and help guide to resource allocation.

\section{Authors' Contributions}

FR, MS, MKF, and AV-A designed the study and were responsible for data acquisition, data analysis, and interpretation. Meanwhile, both authors substantively revised and approved the submitted version of the manuscript.

\section{Conflict of Interest Disclosures}

The authors declare that they have no conflicts of interest.

\section{Ethical Approval}

The present study was approved by the Investigative Review Board at Baqiyatallah University of Medical Sciences, Tehran, Iran, and Shariati Hospital of Tehran University of Medical Sciences, Tehran, Iran.

\section{Funding/Support}

This research did not receive any specific grant from funding agencies in the public, commercial, or not-forprofit sectors.

\section{References}

1. Wang $\mathrm{CH}$, Lin $\mathrm{HC}$, Chang YC, Maa SH, Wang JS, Tang WR. Predictive factors of in-hospital mortality in ventilated intensive care unit: a prospective cohort study. Medicine (Baltimore). 2017;96(51):e9165. doi:10.1097/md.0000000000009165.

2. Marshall JC, Vincent JL, Guyatt G, et al. Outcome measures for clinical research in sepsis: a report of the 2 nd Cambridge Colloquium of the International Sepsis Forum. Crit Care Med. 2005;33(8):1708-1716. doi:10.1097/01. ccm.0000174478.70338.03.

3. Sakr Y, Jaschinski U, Wittebole $X$, et al. Sepsis in intensive care unit patients: worldwide data from the intensive care over nations audit. Open Forum Infect Dis. 2018;5(12):ofy313. doi:10.1093/ofid/ofy313.

4. Singer M, Deutschman CS, Seymour CW, et al. The third international consensus definitions for sepsis and septic shock (Sepsis-3). JAMA. 2016;315(8):801-810. doi:10.1001/ jama.2016.0287.

5. Schultz MJ, Dunser MW, Dondorp AM, et al. Current challenges in the management of sepsis in ICUs in resourcepoor settings and suggestions for the future. Intensive Care Med. 2017;43(5):612-624. doi:10.1007/s00134-017-4750-z.

6. Martin-Loeches I, Levy MM, Artigas A. Management of severe sepsis: advances, challenges, and current status. Drug Des Devel Ther. 2015;9:2079-2088. doi:10.2147/dddt.s78757.

7. Vincent JL, Sakr Y, Sprung CL, et al. Sepsis in European intensive care units: results of the SOAP study. Crit Care Med. 2006;34(2):344-353. doi:10.1097/01. ccm.0000194725.48928.3a

8. Vincent JL, Rello J, Marshall J, et al. International study of the prevalence and outcomes of infection in intensive care units. JAMA. 2009;302(21):2323-2329. doi:10.1001/ jama.2009.1754.

9. Vincent JL, Bihari DJ, Suter PM, et al. The prevalence of nosocomial infection in intensive care units in Europe. Results of the European Prevalence of Infection in Intensive Care (EPIC) Study. EPIC International Advisory Committee. JAMA. 1995;274(8):639-644. doi:10.1001/ jama.1995.03530080055041.

10. Brun-Buisson C, Meshaka P, Pinton P, Vallet B. EPISEPSIS a reappraisal of the epidemiology and outcome of severe sepsis in French intensive care units. Intensive Care Med. 2004;30(4):580-588. doi:10.1007/s00134-003-2121-4.

11. Ibarz M, Boumendil A, Haas LEM, et al. Sepsis at ICU admission does not decrease 30-day survival in very old patients: a posthoc analysis of the VIP1 multinational cohort study. Ann Intensive Care. 2020;10(1):56. doi:10.1186/s13613-02000672-w.

12. Genga KR, Russell JA. Update of sepsis in the intensive care unit. JInnateImmun.2017;9(5):441-455.doi:10.1159/000477419.

13. Chang DW, Tseng $\mathrm{CH}$, Shapiro MF. Rehospitalizations following sepsis: common and costly. Crit Care Med. 2015;43(10):20852093.doi:10.1097/ccm.0000000000001159.

14. Jones TK, Fuchs BD, Small DS, et al. Post-acute care use and hospital readmission after sepsis. Ann Am Thorac Soc. 2015;12(6):904-913. doi:10.1513/AnnalsATS.201411-504OC.

15. Bashar FR, Vahedian-Azimi A, Hajiesmaeili M, et al. Post-ICU psychological morbidity in very long ICU stay patients with ARDS and delirium. J Crit Care. 2018;43:88-94. doi:10.1016/j. jcrc.2017.08.034

16. von Elm E, Altman DG, Egger M, Pocock SJ, Gøtzsche PC, Vandenbroucke JP. The Strengthening the Reporting of Observational Studies in Epidemiology (STROBE) statement: guidelines for reporting observational studies. J Clin Epidemiol. 2008;61(4):344-349. doi:10.1016/j.jclinepi.2007.11.008.

17. Hessler JB, Schäufele M, Hendlmeier I, et al. The 6-Item Cognitive Impairment Test as a bedside screening for dementia in general hospital patients: results of the General Hospital Study (GHoSt). Int J Geriatr Psychiatry. 2017;32(7):726-733. doi:10.1002/gps.4514.

18. Quan H, Sundararajan V, Halfon $\mathrm{P}$, et al. Coding algorithms for defining comorbidities in ICD-9-CM and ICD-10 administrative data. Med Care. 2005;43(11):1130-1139. doi:10.1097/01. mlr.0000182534.19832.83.

19. Wilches Luna EC, Hernández NL, Siriani de Oliveira A, Kenji Nawa R, Perme C, Gastaldi AC. Perme ICU Mobility Score 
(Perme Score) and the ICU Mobility Scale (IMS): translation and cultural adaptation for the Spanish language. Colomb Med (Cali). 2018;49(4):265-272. doi:10.25100/cm.v49i3.4042.

20. Khaleghparast S, Joolaee S, Ghanbari B, Maleki M, Peyrovi $\mathrm{H}$, Bahrani N. A review of visiting policies in intensive care units. Glob J Health Sci. 2015;8(6):267-276. doi:10.5539/gjhs. v8n6p267.

21. Barlow KM, Zangaro GA. Meta-analysis of the reliability and validity of the Anticipated Turnover Scale across studies of registered nurses in the United States. J Nurs Manag. 2010;18(7):862-873. doi:10.1111/j.1365-2834.2010.01171.x.

22. Nagaraj SB, Biswal S, Boyle EJ, et al. Patient-specific classification of ICU sedation levels from heart rate variability. Crit Care Med. 2017;45(7):e683-e690. doi:10.1097/ ccm.0000000000002364.

23. Buysse DJ, Reynolds CF, 3rd, Monk TH, Berman SR, Kupfer DJ. The Pittsburgh Sleep Quality Index: a new instrument for psychiatric practice and research. Psychiatry Res. 1989;28(2):193-213. doi:10.1016/0165-1781(89)90047-4.

24. Sosa FA, Roberti J, Franco MT, Kleinert MM, Patrón AR, Osatnik J. Assessment of delirium using the PRE-DELIRIC model in an intensive care unit in Argentina. Rev Bras Ter Intensiva.
2018;30(1):50-56. doi:10.5935/0103-507x.20180010.

25. Knaus WA, Draper EA, Wagner DP, Zimmerman JE. APACHE II: a severity of disease classification system. Crit Care Med. 1985;13(10):818-829. doi:10.1097/00003465-19860300000013.

26. Vincent JL, Moreno R, Takala J, et al. The SOFA (Sepsis-related Organ Failure Assessment) score to describe organ dysfunction/ failure. On behalf of the Working Group on Sepsis-Related Problems of the European Society of Intensive Care Medicine. Intensive Care Med. 1996;22(7):707-710. doi:10.1007/ bf01709751.

27. Kline RB. Software review: software programs for structural equation modeling:Amos, EQS, and LISREL.JPsychoeducAssess 1998;16(4):343-364. doi:10.1177/073428299801600407.

28. Colpan A, Akinci E, Erbay A, Balaban N, Bodur H. Evaluation of risk factors for mortality in intensive care units: a prospective study from a referral hospital in Turkey. Am J Infect Control. 2005;33(1):42-47. doi:10.1016/j.ajic.2004.09.005.

29. Chen YC, Lin SF, Liu CJ, Jiang DD, Yang PC, Chang SC. Risk factors for ICU mortality in critically ill patients. J Formos Med Assoc. 2001;100(10):656-661. 